\title{
Título da página eletrónica: CIES Football
} Observatory

URL: http://www.football-observatory.com

\section{Carlos Nolasco}

\section{OpenEdition}

\section{Journals}

Edição electrónica

URL: http://journals.openedition.org/rccs/7595

DOI: $10.4000 /$ rccs.7595

ISSN: 2182-7435

\section{Editora}

Centro de Estudos Sociais da Universidade de Coimbra

Edição impressa

Data de publição: 1 setembro 2018

Paginação: 207-208

ISSN: 0254-1106

\section{Refêrencia eletrónica}

Carlos Nolasco, «Título da página eletrónica: CIES Football Observatory », Revista Crítica de Ciências Sociais [Online], 116 | 2018, posto online no dia 31 julho 2018, consultado o 25 setembro 2020. URL : http://journals.openedition.org/rccs/7595; DOI : https://doi.org/10.4000/rccs.7595 


\section{Espaço Virtual}

\section{Título da página eletrónica: CIES Football Observatory URL: http://www.football-observatory.com}

O CIES Football Observatory é um site especializado na análise estatística do futebol. Foi fundado em 2005, por Raffaele Poli e Loïc Ravenel, aos quais se juntou Roger Besson, e é apoiado e enquadrado pelo Centre International d'Étude du Sport (Suíça). O prestígio deste Observatório reflete-se nas inúmeras solicitações feitas por entidades como a Fédération Internationale de Football Association (FIFA), a Union of European Football Associations (UEFA), ou o Comité Olímpico Internacional.

O trabalho realizado no CIES Footbal Observatory foca-se em três eixos temáticos: análise técnica das competências e performances de futebolistas; ponderação científica dos valores económicos estimados nas transferências dos jogadores; análise demográfica do mercado de trabalho futebolístico. O espaço de observação incide predominantemente nas big five leagues, em concreto as ligas da Alemanha, Espanha, França, Inglaterra e Itália, mas recorrentemente são feitas análises sobre o futebol europeu e mundial.

A arquitetura do site é composta por diversas páginas, correspondentes aos vários tipos de informação trabalhada no Observatório. Em Posts, são publicadas semanalmente mensagens breves relativas a temas que estão a ser trabalhados pela equipa do Observatório, cifrando-se em mais de 230 os posts publicados até ao início de junho de 2018. A página Reports é referente à publicação de relatórios sobre as tendências financeiras, demográficas e técnico-táticas da atividade futebolística.
Em Values, determinam-se as cotações de mercado que jogadores e equipas têm durante um determinado período. $\mathrm{Na}$ página Profile, é desenhado o perfil de competências futebolísticas dos jogadores em função do seu desempenho nos últimos mil minutos de jogo. Considerando diversos desempenhos coletivos e individuais, a página Rankings estabelece um escalonamento de vários itens de equipas e jogadores. Finalmente, a entrada Tools disponibiliza três instrumentos que permitem observar detalhadamente aspetos do futebol, nomeadamente uma base de dados com perfis de jogadores, uma calculadora do valor de transferência de futebolistas, e um atlas digital de vários aspetos demográficos do futebol.

O CIES Football Observatory apresenta fatores distintivos relativamente à generalidade dos sites sobre futebol que se encontram na internet: os indicadores que disponibiliza são diversificados, permitindo um retrato amplo da forma como o futebol acontece; esses dados são válidos e confiáveis, desde logo porque são produzidos por especialistas e resultam da aplicação de metodologias científicas; a regularidade das informações disponibilizadas permite elaborar séries estatísticas longas e assim observar tendências de médio e longo prazo na atividade futebolística.

A crítica mais significativa que se pode fazer ao site está relacionada com a ausência de análises qualitativas e reflexivas sobre o futebol. Como referido, os dados estatísticos apresentados são 
muito relevantes, em particular os dados demográficos, que permitem tirar ilações sociológicas sobre a relevância do futebol nos diversos países em análise, bem como as dinâmicas económicas que determinam as tendências do futebol contemporâneo. Contudo, o CIES Football Observatory queda-se apenas pelo tratamento e apresentação estatística da informação, o que retira profundidade às análises produzidas.

A importância do Observatório é constatável a vários níveis: a sua newsletter tem mais de 25 mil subscritores; o tráfico do site foi, em 2017, superior a $750 \mathrm{mil}$ visitas; a sua conta de Twitter tem cerca de 8,5 milhões de seguidores. Mas ainda mais relevante é o facto de a informação estatística produzida pelo CIES Football Observatory ser replicada pelos órgãos de comunicação social, e permitir fundamentar argumentos em todos os trabalhos académicos que incidem sobre o tema futebol.
O site é também incontornável para todos os adeptos de futebol esclarecidos, que tenham um posicionamento crítico sobre o futebol que observam.

O trabalho realizado por este Observatório, que incide sobre o futebol de alta competição, principalmente na Europa, revela os traços marcantes do futebol contemporâneo: o futebol como um negócio, onde se rentabilizam financeiramente jogos e jogadores; os jogadores como mercadoria, em mobilidade num intenso mercado migratório de trabalho futebolístico; a globalização do futebol, envolvendo todos os espaços geográficos nesta dinâmica. Produzindo um conhecimento de referência sobre o futebol, os dados do CIES Football Observatory mostram a forma como o futebol se produz e é reproduzido por dinâmicas sociais amplas consoante os contextos em que ocorre.

Carlos Nolasco

\section{Título da página eletrónica: The Turbulent World of Middle East Soccer URL: https://mideastsoccer.blogspot.com}

Por definição, futebol é política. E tudo o que envolva este jogo, nas regiões do Médio Oriente e do norte de África, tem uma origem e uma índole política. Esta é a base e o olhar de James M. Dorsey no blogue The Turbulent World of Middle East Soccer, um dos mais vistos a nível mundial no que diz respeito a futebol nas referidas regiões. Investigador Sénior na Universidade Tecnológica de Nanyang, em Singapura, e codiretor do Institute for Fan Culture da Universidade de Würzburg, na Alemanha, Dorsey publica regularmente, desde 2011, extensas e controversas análises sobre futebol, entendendo os estádios como "simbólicos campos de batalha pela liberdade política; oportunidade económica; identidade nacional, étnica e religiosa; e pelos direitos de género".

O futebol, no Médio Oriente e no norte de África, assume um cariz muito próprio e específico, como espaço de contestação aos regimes autoritários e à falta de liberdades cívicas. O Catar, enquanto anfitrião do Campeonato do Mundo de Futebol de 2022, é um dos temas recorrentes no blogue. Dorsey afirma que "é o futuro de toda uma região" que está em causa com o Mundial de 2022 e não simplesmente um mero megaevento desportivo. Tal como referido nas informações sobre o blogue e o autor, Dorsey "explora o papel do futebol num momento de 
transição entre a lei autocrática e uma sociedade [árabe e norte-africana] mais aberta", entrecruzando futebol e atualidade política.

Mas o autor do livro The Turbulent World of Middle East Soccer, ${ }^{1}$ inspirado no blogue homónimo, não se fica pela mera descrição de acontecimentos, tomando clara posição a favor de uma maior liberdade (democrática) por parte dos Estados norte-africanos e árabes, tendo como pano de fundo o futebol nas suas múltiplas dimensões. As tomadas de posição e exposição mediática de Dorsey já o colocaram na lista de individualidades impedidas de entrar em alguns países do Médio Oriente, sobretudo nos mais conservadores e autoritários, como represália pelas suas opiniões, geralmente contrárias às visões e posicionamentos políticos desses Estados.

Francisco Pinbeiro

\section{Carlos Nolasco}

Centro de Estudos Sociais da Universidade de Coimbra

Colégio de S. Jerónimo, Largo D. Dinis, Apartado 3087, 3000-995 Coimbra, Portugal

Contacto: cmsnolasco@ces.uc.pt

\section{Francisco Pinheiro}

Centro de Estudos Interdisciplinares do Século XX da Universidade de Coimbra - CEIS20

Rua Filipe Simões, 33, 3000-186 Coimbra, Portugal

Contacto: franciscopinheiro72@gmail.com

\footnotetext{
${ }^{1}$ James M. Dorsey (2016), The Turbulent World of Middle East Soccer. London: C. Hurst \& Co Publishers Ltd.
} 
